\title{
Dehydrogenation of 1-Phenylethanol Catalyzed by Nickel(II)diphosphine Complexes
}

\author{
Reshma Geetha, ${ }^{1}$ Meenu Kumar, ${ }^{1}$ Naveen V. Kulkarni ${ }^{1,2 *}$ \\ and William D. Jones ${ }^{2 \star}$ \\ ${ }^{1}$ Department of Chemistry, Amrita Vishwa Vidyapeetham, Amritapuri, Kerala 690525, INDIA \\ ${ }^{2}$ Department of Chemistry, University of Rochester, Rochester, New York 14450, USA \\ *Corresponding author: E-mail: dr.naveenvk@gmail.com; naveenvkulkarni@am.amrita.edu (NVK) \\ jones@chem.rochester.edu (WDJ)
}

Received: 05-12-2021

\begin{abstract}
Catalytic efficacy of the nickel(II)-diphosphine systems in the dehydrogenation of 1-phenylethanol to acetophenone under acceptorless conditions was investigated. Steric and electronic factors of the phosphine ligands were found to play an important role in the catalysis, while the nature of the base used and the reaction conditions, viz. time, tempe rature, and stoichiometry, have also shown major influence. Based on the preliminary analysis, a homogeneous pathway, perhaps involving nickel hydride species, was proposed. Due to the gradual disintegration of the catalytic species, deterioration of catalytic activity was observed resulting into low to moderate conversions. Among the series of catalysts examined, the highest conversion of $52 \%$ was exhibited by the catalyst $\mathbf{C 4}$, dichloro(1,2-bis(diphenylphosphino)ethane) nickel(II) (5 mol\%), when loaded with $50 \mathrm{~mol} \%$ of sodium ethoxide in toluene at $120^{\circ} \mathrm{C}$.
\end{abstract}

Keywords: Acceptorless dehydrogenation; dehydrogenation of alcohol; nickel(II)catalyst; 1,2 bis(alkyl/arylphosphino) alkane. homogeneous catalysis; Catalyst disintegration.

\section{Introduction}

In recent years the acceptorless dehydrogenation process has gained much attention in academic and industrial research. It provides an efficient and atom-economical route for converting alcohols into synthetically useful carbonyl compounds, without the use of a sacrificial hydrogen acceptor. Moreover, the only byproduct formed in the reaction is highly valuable molecular hydrogen. ${ }^{1-3}$ Due to the vast significance of this catalytic reaction, a variety of homogeneous catalysts has been developed and employed in this process. It is often seen that the catalysts containing precious metal centres, viz., $\mathrm{Ru}, \mathrm{Rh}$, Ir, and Os have exhibited better performance, ${ }^{4-7}$ nevertheless, with the meticulous tuning of structural features of the catalyst and reaction conditions, systems containing sustainable metals such as $\mathrm{Fe}$, Co and Mn were also shown to exhibit comparable activities in this catalytic reaction. ${ }^{8-15}$ However, in comparison, nickel-based catalysts are underexplored in dehydrogenation chemistry; examples of single-molecule nickel catalysts capable of mediating acceptorless dehydrogenation of alcohols are extremely scarce. Key examples are the $\mathrm{Ni}(\mathrm{II})$ complexes supported by tris(3,5-dimethylpyrazolyl)borate and 2-hydroxyquinoline mixed ligands developed by Jones et al. ${ }^{16}$ and $\mathrm{Ni}(\mathrm{II})$ complexes derived from 2,6-bis(diethylaminomethyl)pyridine) pincer ligand reported by Zhang et al. ${ }^{17}$ It is important to notice that these catalysts involve either exotic ligand systems or special reaction conditions to achieve the desired reactivity. This prompted us to look for simple nickel-based systems, which can efficiently catalyse dehydrogenation of alcohols under mild to moderate reaction conditions. Incidentally, diphosphine nickel(II)chloride complexes attracted us due to their simple synthetic protocols, stability and well-established catalytic profile. ${ }^{18-25}$ Here in this article, we describe the use of diphosphine nickel(II)chloride complexes in the acceptorless dehydrogenation of alcohols.

\section{Experimental}

All of the synthesis and catalysis procedures were performed under $\mathrm{N}_{2}$ atmosphere using Schlenk line techniques. All the solvents and reagents used in this work were 
purified \& dried using standard protocols ${ }^{26}$ and stored over molecular sieves (4 Å). Ligands, bis(dimethylphosphaneyl)ethane (L1), bis(diethylphosphaneyl)ethane (L2), bis(diphenylphosphaneyl)ethane (L4), triphenylphosphine (L5), bis(diphenylphosphaneyl)methane (L6), 1,3-bis(diphenylphosphaneyl)propane (L7) were purchased from Sigma Aldrich (Merck). Ligand, bis(diisopropylphosphaneyl)ethane (L3) ${ }^{27}$ and the nickel(II)catalysts, [1,2-bis(dimethylphosphino)ethane] dichloronickel(II) (C1) ${ }^{28}$ [1,2-bis(diethylphosphino)ethane]dichloronickel(II) (C2), ${ }^{28,29}$ [1,2 bis(diisopropylphosphino)-ethane] dichloronickel(II) (C3), ${ }^{30} \quad$ [1,2-bis(diphenylphosphino) ethane]dichloronickel(II) (C4), ${ }^{28,31}$ dichlorobis(triphenylphosphine)nickel(II) (C5), ${ }^{32}$ bis(diphenylphosphino) methane] dichloronickel(II) (C6) ${ }^{31}$ and bis(diphenylphosphino)propane]dichloronickel(II) $(\mathbf{C} 7)^{31}$, were prepared by following the reported protocols.

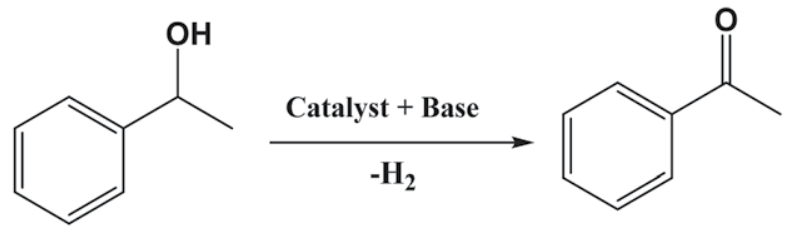

Scheme 1: Catalytic acceptorless dehydrogenation of 1-phenyl ethanol

In a typical catalytic acceptorless dehydrogenation reaction (Scheme 1), $0.05 \mathrm{mmol}$ of nickel(II)phosphine catalyst (C1-C7) and $0.5 \mathrm{mmol}$ of base were loaded in a two necked Schlenk flask equipped with a water condenser under $\mathrm{N}_{2}$ atmosphere. $2 \mathrm{~mL}$ of toluene (dried over benzophenone-sodium) was added and the mixture was stirred for a couple of minutes. $0.122 \mathrm{~mL}(1 \mathrm{mmol})$ of 1-phenylethanol was added to the catalytic mixture using a syringe and the Schlenk flask was kept in a $120^{\circ} \mathrm{C}$ preheated oil-bath and stirred vigorously for $16 \mathrm{~h}$. A continuous bubbling of $\mathrm{N}_{2}$ gas was maintained throughout the reaction. After the scheduled period of time, the reaction was stopped, allowed to cool to room temperature and opened to air. The product yield was analysed by gas chromatography analysis (vide infra) and in some cases, also by ${ }^{1} \mathrm{H}$ NMR spectroscopic analysis (vide infra). Product isolation was done by running the catalytic mixture through a silica gel column using ethyl acetate:hexane (1:3) eluant. The results are summarized in Table 1.

GC analysis details: After the reaction, the reaction mixture was diluted with $9 \mathrm{~mL}$ of dichloromethane and filtered through a short plug of Celite. $360 \mu \mathrm{L}$ of filtrate and $25 \mu \mathrm{L}$ of tridecane (internal standard) were taken in $3 \mathrm{~mL}$ of dichloromethane and analyzed on Shimadzu GC-17A FID instrument, using Agilent DB-WAXETR column (30 $\mathrm{m} \times 0.25 \mathrm{~mm}$, thickness $0.50 \mu \mathrm{m})$ using helium as a carrier gas. Method used: starting oven temperature, $50^{\circ} \mathrm{C}$ (hold for $5 \mathrm{~min}$ ); maximum temperature, $240^{\circ} \mathrm{C}$; heating rate, 15 ${ }^{\circ} \mathrm{C} / \mathrm{min}$ (hold for $5 \mathrm{~min}$ ); column pressure: $24.5 \mathrm{psi}$; total flow: $273 \mathrm{~mL} / \mathrm{min}$, column flow: $2.64 \mathrm{~mL} / \mathrm{min}$, split ratio: 100, linear velocity: $49 \mathrm{~cm} / \mathrm{sec}$.

${ }^{1} \mathrm{H}$ NMR spectroscopic analysis details: Reaction mixture was evacuated under a weak vacuum to partially remove the solvent (toluene), followed by the addition of $\sim 0.3 \mathrm{~mL}$ of $\mathrm{CDCl}_{3}$ and thorough mixing. An aliquot from this solution was taken in an NMR tube, diluted with $\mathrm{CDCl}_{3}$ and analyzed on a Bruker Ascend $500 \mathrm{NMR}$ spectrometer operating at $500 \mathrm{MHz}$ at RT). Relative area of integration of the methyl protons of 1-phenylethanol<smiles>C[PH]1(C)CC[PH](C)(C)[PH]1(Cl)Cl</smiles>

C1<smiles>CC[PH]1(Cl)CC[PH](CC)(CC)[N+]1(Cl)Cl</smiles>

$\mathrm{C} 2$<smiles>CC(C)[N+]1(C)P(Cl)(Cl)(C(C)C)CCP1(Cl)(Cl)C(C)C</smiles>

C3<smiles>Cl[N+]1(c2ccccc2)[PH](Cl)(c2ccccc2)CC[PH]1(Cl)c1ccccc1</smiles>

C4<smiles>Cl[N+](Cl)(P(c1ccccc1)c1ccccc1)[PH](c1ccccc1)(c1ccccc1)c1ccccc1</smiles>

C5<smiles>ClP1C[PH](Cl)(c2ccccc2)[N+]1(Cl)c1ccccc1</smiles>

C6<smiles>Cl[N+]1(Cl)P(c2ccccc2)CCC[PH]1(Cl)c1ccccc1</smiles>

C7

Figure 1: Nickel(II)diphosphine complexes used in the current study. 
(doublet or broad, $\sim \delta 1.48$ ) and acetophenone (singlet, $\delta 2.57)$ were considered to calculate the percent of conversion.

${ }^{31} \mathrm{P}\left\{{ }^{1} \mathrm{H}\right\}$ NMR analysis was done in $\mathrm{CDCl}_{3}$ on a Bruker AMX 400 spectrometer operating at $162 \mathrm{MHz}$ at RT; Chemical shift values are reported with reference to the external standard, $\mathrm{H}_{3} \mathrm{PO}_{4}$. In the analysis of catalytic mixture, an aliquot of reaction mixture was taken in NMR tube, added with $\mathrm{CDCl}_{3}$ and used for analyses.

\section{Results and Discussion}

Among the nickel(II)complexes supported by the substituted diphosphinoethane ligands (Figure 1), we found that the system bearing phenyl substitutions (i.e., C4) exhibited better activity, converting $52 \%$ of 1 -phenylethanol to acetophenone, under the current reaction conditions (Entry 4, Table 1). The systems having methyl (C1) and isopropyl (C3) substitutions on the phosphorus donors yielded only 12 and $14 \%$ of acetophenone, respectively (Entries 1 and 3 in Table 1). With the nickel(II)diphosphine system substituted with ethyl groups on phosphorus, $30 \%$ conversion was observed (Entry 2, Table 1). This indicates the significant influence of electronic effects of the ligands on the stability and reactivity of the catalyst system. ${ }^{33,34}$ Incidentally, anhydrous nickel(II)chloride in the absence of any phosphine ligand showed no detectable conversions under our reaction conditions (Entry 8, Table 1). Sole use of the ligand, bis(diphenylphosphaneyl)ethane
(L4) did not provide any catalytic conversion (Entry 9, Table 1). Sodium ethoxide (50 mol\%) in absence of nickel catalyst also did not show any detectable conversion (Entry 10, Table 1).

Table 1: Catalysis data for acceptorless dehydrogenation of 1-phenylethanol to yield acetophenone; catalyzed by nickel(II)diphosphine complexes C1-C7.*

\begin{tabular}{|c|c|c|c|}
\hline Entry & Catalyst & Conversion (\%) & Yield $(\%)^{\$}$ \\
\hline 1 & C1 & 12 & - \\
\hline 2 & $\mathrm{C} 2$ & 30 & 24 \\
\hline 3 & C3 & 14 & - \\
\hline 4 & $\mathrm{C} 4$ & 52 & 45 \\
\hline 5 & C5 & 30 & 25 \\
\hline 6 & C6 & 21 & 16 \\
\hline 7 & C7 & 34 & 26 \\
\hline 8 & $\mathrm{NiCl}_{2}$ & NIL & - \\
\hline 9 & L4 & NIL & - \\
\hline 10 & - & NIL & - \\
\hline \multicolumn{4}{|c|}{$\begin{array}{l}{ }^{*} \text { Catalytic reactions are conducted in dry toluene with } 1 \mathrm{mmol} \text { of } \\
1 \text {-phenyl ethanol, } 0.05 \mathrm{mmol} \text { of catalyst }(5 \mathrm{~mol} \%) \text { and } 0.5 \mathrm{mmol} \\
(0.027 \mathrm{~g}, 50 \mathrm{~mol} \%) \text { of } \mathrm{NaOEt} \text {, at } 120^{\circ} \mathrm{C} \text { (oil bath temperature) for } \\
16 \mathrm{~h} \text {, under the slow, continuous bubbling of nitrogen gas. }{ }^{*} \text { Data } \\
\text { from GC analysis (Average value of two duplicate experiments). } \\
{ }^{\$} \text { Isolated yield. }\end{array}$} \\
\hline
\end{tabular}

Further, we examined the efficacy of different phosphinonickel(II)chloride complexes, bearing phenyl substituents on the phosphorus but with varying spacer groups in the acceptorless dehydrogenation of 1-pheny-

Table 2: Catalysis data for acceptorless dehydrogenation of 1-phenylethanol to yield acetophenone; catalyzed by the nickel(II)diphosphine complex C4 under various reaction conditions.

\begin{tabular}{|c|c|c|c|c|c|}
\hline Entry & Catalyst (mol\%) & Base (mol\%) & Reaction conditions & Conversion $(\%)^{*}$ & Yield $(\%)^{\#}$ \\
\hline 1 & C4 (5) & NaOEt (50) & $120^{\circ} \mathrm{C}$ in Toluene, $16 \mathrm{~h}$, No $\mathrm{N}_{2}$ bubbling. & 8 & - \\
\hline 2 & C4 (5) & $\mathrm{NaOMe}(50)$ & $120^{\circ} \mathrm{C}$ in Toluene, $16 \mathrm{~h}$, With $\mathrm{N}_{2}$ bubbling. & 23 & 15 \\
\hline 3 & C4 (5) & $\mathrm{KOH}(50)$ & $120^{\circ} \mathrm{C}$ in Toluene, $16 \mathrm{~h}$, With $\mathrm{N}_{2}$ bubbling. & 4 & - \\
\hline 4 & C4 (5) & $\mathrm{KO}^{t} \mathrm{Bu}(50)$ & $120^{\circ} \mathrm{C}$ in Toluene, $16 \mathrm{~h}$, With $\mathrm{N}_{2}$ bubbling. & 50 & 45 \\
\hline 5 & C4 (5) & NaOEt (25) & $120^{\circ} \mathrm{C}$ in Toluene, $16 \mathrm{~h}$, With $\mathrm{N}_{2}$ bubbling. & 22 & 16 \\
\hline 6 & C4 (5) & NaOEt (10) & $120^{\circ} \mathrm{C}$ in Toluene, $16 \mathrm{~h}$, With $\mathrm{N}_{2}$ bubbling. & 11 & - \\
\hline 7 & C4 (10) & NaOEt (50) & $120^{\circ} \mathrm{C}$ in Toluene, $16 \mathrm{~h}$, With $\mathrm{N}_{2}$ bubbling. & 56 & 48 \\
\hline 8 & C4 (2) & $\mathrm{NaOEt}(50)$ & $120^{\circ} \mathrm{C}$ in Toluene, $16 \mathrm{~h}$, With $\mathrm{N}_{2}$ bubbling. & 12 & - \\
\hline 9 & C4 (5) & NaOEt (50) & $120^{\circ} \mathrm{C}$ in Toluene, $24 \mathrm{~h}$, With $\mathrm{N}_{2}$ bubbling. & 54 & 45 \\
\hline 10 & C4 (5) & NaOEt (50) & $120^{\circ} \mathrm{C}$ in Toluene, $48 \mathrm{~h}$, With $\mathrm{N}_{2}$ bubbling. & 55 & 45 \\
\hline 11 & C4 (5) & NaOEt (50) & $120^{\circ} \mathrm{C}$ in Toluene, $8 \mathrm{~h}$, With $\mathrm{N}_{2}$ bubbling. & 32 & 24 \\
\hline 12 & C4 (5) & NaOEt (50) & $25^{\circ} \mathrm{C}$ in Toluene, $16 \mathrm{~h}$, With $\mathrm{N}_{2}$ bubbling. & Traces & - \\
\hline 13 & C4 (5) & NaOEt (50) & $60^{\circ} \mathrm{C}$ in Toluene, $16 \mathrm{~h}$, With $\mathrm{N}_{2}$ bubbling. & 8 & - \\
\hline 14 & C4 (5) & NaOEt (50) & $140^{\circ} \mathrm{C}$ in Xylenes, $16 \mathrm{~h}$, With $\mathrm{N}_{2}$ bubbling. & 54 & 45 \\
\hline $15^{\psi}$ & C4 (5) & NaOEt (50) & $120^{\circ} \mathrm{C}$ in Toluene, $16 \mathrm{~h}$, With $\mathrm{N}_{2}$ bubbling. & 46 & 38 \\
\hline $16^{¥}$ & C4 (5) & NaOEt (50) & $120^{\circ} \mathrm{C}$ in Toluene, $16 \mathrm{~h}$, With $\mathrm{N}_{2}$ bubbling. & 54 & 44 \\
\hline $17^{\# \#}$ & C4 (5) & NaOEt (50) & $120^{\circ} \mathrm{C}$ in Toluene, $16 \mathrm{~h}$, With $\mathrm{N}_{2}$ bubbling & 52 & 43 \\
\hline $18^{\$}$ & C4 (5) & NaOEt (50) & $120^{\circ} \mathrm{C}$ in Toluene, $16 \mathrm{~h}$, With $\mathrm{N}_{2}$ bubbling. & 51 & 43 \\
\hline
\end{tabular}

${ }^{*}$ Data from GC analysis (Average value of two duplicate experiments; Percent of conversion obtained from ${ }^{1} \mathrm{H}$ NMR spectroscopic analysis were comparable with the GC data, within the difference of $\pm 5 \%) .{ }^{*}$ Isolated yield. ${ }^{\psi} 1$-(p-tolyl)ethanol was used as substrate. ¥ 1-(4-fluorophenyl)ethanol was used as substrate. ${ }^{\# \#} \mathrm{~A}$ drop of metallic mercury $(\sim 50 \mathrm{mg})$ was added to the reaction mixture prior heating (Mercury poisoning test). ${ }^{\$} \mathrm{~A}$ drop of carbon disulphide $(\sim 0.1 \mathrm{~mL})$ was added to the reaction mixture prior heating $\left(\mathrm{CS}_{2}\right.$ poisoning test $)$. 
lethanol, under the same reaction conditions. It was found that the phenylphosphine(II)nickel system with a propyl (three-carbons) spacer (C7) exhibited better activity yielding $34 \%$ of acetophenone (Entry 7, Table 1), over the system bearing a methylene (one-carbon) spacer (C6), which could dehydrogenate only $21 \%$ of the substrate (Entry 6, Table 1). On the other hand, the catalytic activity of the nickel catalyst containing two triphenylphosphine ligands (C5) was found to fall between the complexes C6 and C7 ( $30 \%$ conversion, Entry 5, Table 1). Nevertheless, the complex, C4, which bears an ethyl (two carbon) spacer was found to be the best catalyst among the systems employed in this study (Entry 4, Table 1), hence was chosen for the further exploration. The higher activity of the complex $\mathbf{C 4}$ can be correlated with its higher stability. Due to the presence of a stable five membered coordination ring (ring size effect) and near ideal bite angle $\beta$, this system is expected to be stabilized electronically. ${ }^{34-38}$

Continuous bubbling of dry nitrogen/argon gas throughout the reaction period is found to be key to expel the molecular hydrogen produced and to access the better conversions. ${ }^{16} \mathrm{~A}$ drastic decrease in the yield $(\sim 8 \%)$ was observed, otherwise, due to the superseding backword, hydrogenation reaction ${ }^{31}$ (Entry 1, Table 2). Since alcohol dehydrogenation is a thermodynamically uphill process, ${ }^{39}$ continuous removal of hydrogen gas will have a positive thermodynamic contribution and can favour the forward reaction. ${ }^{40}$

The nature and stoichiometric ratio of the base used play an important role in the dehydrogenation-hydrogenation catalytic reactions. ${ }^{41}$ In the current studies, sodium ethoxide was found to be the most compatible base; replacing it with sodium methoxide, under similar reaction conditions, yielded lower conversion viz., 23\% (Entry 2, Table 2). Potassium hydroxide was found to be unsuitable for our system, which produced only about $4 \%$ of acetophenone (Entry 3, Table 2), while potassium tert-butoxide provided a comparable yield (50\% conversion, Entry 4, Table 2). Lowering the loading of the base sodium ethoxide to 25 mol\% (Entry 5, Table 2) or $10 \mathrm{~mol} \%$ (Entry 6, Table 2) resulted in a decrease in reactivity, yielding $22 \%$ and $11 \%$ of the product, respectively, indicating that the higher loading of $50 \mathrm{~mol} \%$ of base is essential to maintain the catalytically active species during the course of the reaction. ${ }^{41,42}$

In an attempt to improve the catalytic conversion, we tried varying the catalyst loading, keeping the stoichiometry of the sodium ethoxide unchanged ( $50 \mathrm{~mol} \%)$ under the same reaction conditions. When the catalyst loading was increased to $10 \mathrm{~mol} \%$ (Entry 7, Table 2) a slight improvement in the conversion (56\%) was observed, indicating that higher catalyst loading is necessary to get better conversions. Conversely, when catalyst loading was reduced to $2 \mathrm{~mol} \%$ (Entry 8, Table 2), a drastic decrease in the activity was observed, yielding only $12 \%$ conversion.

All the catalytic reactions in the above studies were run overnight (16h). In anticipation of increasing the con- version, we extended the reaction period to $24 \mathrm{~h}$ (Entry 9, Table 2). This resulted in a slight enhancement in the conversion providing $54 \%$ of the product. However, further extension of the reaction period to $48 \mathrm{~h}$ did not show any significant improvement in the yield (Entry 10, Table 2 ), indicating gradual degeneration of the catalytic species over time. ${ }^{42}$ On the other hand, when the reaction time was limited to $8 \mathrm{~h}$, only $32 \%$ conversion was observed (Entry 11 , Table 2).

To overcome the thermodynamic constraints, the process of dehydrogenation of alcohols often requires higher reaction temperatures ${ }^{16}$ or a suitable acceptor. ${ }^{43}$ In our current acceptorless reaction conditions, we found that a higher reaction temperature, $v i z .120^{\circ} \mathrm{C}$, is required to attain higher conversions. When the catalytic reaction was carried at room temperature (Entry 12, Table 2), no detectable catalytic activity was observed and the reaction conducted at $60{ }^{\circ} \mathrm{C}$ (Entry 13, Table 2) yielded only 8\% conversion. On the other hand, when the reaction was conducted at higher temperature $\left(140^{\circ} \mathrm{C}\right.$, in xylenes), a slight improvement in the activity was observed, providing $54 \%$ conversion (Entry 14, Table 2).

Further, we examined the efficacy of our catalytic system in the dehydrogenation of a couple of para substituted 1-phenylethanol motifs. The substrate containing an electron donating group, 1-( $p$-tolyl)ethanol (Entry 15, Table 2), yielded slightly lower conversion (slower reaction) compared to the substrate bearing an electron withdrawing substituent, 1-(4-fluorophenyl)ethanol (Entry 16, Table 2) under the same reaction conditions. This reactivity pattern is in line with the earlier observations involving nickel-based catalysts. ${ }^{16}$ Due to the moderate reactivity of the catalyst system, we did not try to expand the substrate scope to other alcholols.

It has recently been shown that nickel(II)diphosphine complexes are very good catalysts in transfer hydrogenation, where various substituted ketones were converted nearly quantitatively to the corresponding alcohols using isopropanol as a sacrificial hydrogen donor as well as a solvent. ${ }^{31}$ However, in the current acceptorless conditions, in spite of our attempts with varying reaction stoichiometry and conditions, we were not able to improve the conversion. Gradual disintegration of the catalyst under the reaction conditions is envisaged to be the main cause for the deterioration of catalytic activity. However, the dominant backword hydrogenation reaction could also have some key role to play. ${ }^{16,31}$ During the course of the catalytic dehydrogenation reaction, a change in the colour of the reaction mixture from yellow to dark brown was observed, which is a typical indication for the formation of $\mathrm{Ni}(0)$ related nanoclusters. ${ }^{31,44}$ In order to investigate if the $\mathrm{Ni}(0)$ nanoclusters have any role to play in the catalysis, a mercury poisoning test (Entry 15, Table 2), ${ }^{16,47}$ as well as a carbon disulphide poisoning test (Entry 16, Table 2) ${ }^{46}$ were performed. However, both tests turned out to be negative, as no significant difference in the catalytic reactivity/ 
conversion was observed, thus, ruling out any contribution from a metal nano-particle mediated heterogeneous pathway. ${ }^{41}$ Further, in the ${ }^{31} \mathrm{P}\left\{{ }^{1} \mathrm{H}\right\}$ NMR spectroscopic analysis, we found that, a single signal at $\delta 57.1$ observed for the complex $\mathrm{C} 4$, experiences a significant shift upon addition of 2 equivalent amount of 1-phenyl ethanol and heating to $60{ }^{\circ} \mathrm{C}$ for five minutes with thorough shaking, forming a peak at $\delta 33.0$ indicating the formation of a new compound, possibly an alkoxide species. Same signal $(\sim \delta$ 33.0) was observed in the ${ }^{31} \mathrm{P}\left\{{ }^{1} \mathrm{H}\right\}$ NMR spectrum of the catalytic mixture, when recorded at the initial stages (within $5 \mathrm{~min}$ ), suggesting the formation of the same species as in the catalytic conditions. However, at the end of the catalytic reaction $(24 \mathrm{~h})$, the appearance of a new signal at $\delta 198.5$ along with the signal at $\sim \delta 33.0$ indicates partial dissociation of the intermediate compound. All of these observations strongly suggest a catalytic mechanism involving a homogeneous route, perhaps mediated by nickel alkoxide and nickel hydride intermediates, as envisaged in the previous studies. ${ }^{16,31,47}$

\section{Conclusion}

Overall, we have explored the catalytic efficacy of the nickel(II)diphosphine systems in the dehydrogenation of 1-phenylethanol under acceptorless conditions. Steric and electronic factors of the phosphine ligands were found to play an important role in the catalysis along with the nature of the base used, as well as the reaction conditions. The catalytic reaction was found to follow a homogeneous pathway, presumably involving nickel hydride species. The catalytic reaction suffers mostly due to the disintegration of the catalytic species, providing only low to moderate conversions. We are currently working on isolation of the nickel hydride species, as structural characterization of these reactive intermediates could help us in understanding the mechanistic aspects of the catalytic reaction which would, indeed, help in improving the efficacy and expanding the substrate scope of the catalytic systems. ${ }^{48,49}$ Perhaps, these systems can be tuned to efficiently promote Guerbet upgrading of ethanol to $\mathrm{n}$-butanol, which is a reaction of great commercial importance and of our primary focus. ${ }^{41,50}$

\section{Acknowledgments}

This work was partly supported by the NSF under the CCI Center for Enabling New Technologies through Catalysis (CENTC), CHE-1205189. NVK thanks Science and Engineering Research Board (SERB) for the TARE grant (TAR/2018/000881) and Prof. A. G. Samuelson, Indian Institute of Science, Bengaluru for his support. WDJ acknowledges partial summer support from the U.S. Department of Energy, Basic Energy Sciences (BES) Chemical Sciences, Geosciences, \& Biosciences (CSGB) Division (DE-SC0020230).

\section{References}

1. R. H. Crabtree, Chem. Rev. 2017, 117, 9228-9246. DOI:10.1021/acs.chemrev.6b00556

2. P. Pandey, I. Dutta, J. K. Bera, Proc. Natl. Acad. Sci., India, Sect. A Phys. Sci. 2016, 86, 561-579. DOI:10.1007/s40010-016-0296-7

3. G. Guillena, D. J. Ramon, M. Yus, Chem. Rev. 2010, 110, 1611-1641. DOI:10.1021/cr9002159

4. G. Zeng, S. Sakaki, K.-I. Fujita, H. Sano, R. Yamaguchi, ACS Catal. 2014, 4, 1010-1020. DOI:10.1021/cs401101m

5. T. Zweifel, J. V. Naubron, H. Grützmacher, Angew. Chem., Int. Ed. 2009, 48, 559-563. DOI:10.1002/anie.200804757

6. I. Mena, M. A. Casado, V. Polo, P. Garcia-Orduña, F. J. Lahoz, L. A. Oro, Angew. Chem., Int. Ed. 2012, 51, 8259-8263. DOI:10.1002/anie.201202936

7. M. Bertoli, A. Choualeb, A. J. Lough, B. Moore, D. Spasyuk, D. G. Gusev, Organometallics 2011, 30, 3479-3482. DOI:10.1021/om200437n

8. S. Chakraborty, W. W. Brennessel, W. D. Jones, J. Am. Chem. Soc. 2014, 136, 8564-8567. DOI:10.1021/ja504523b

9. S. Chakraborty, P. O. Lagaditis, M. Förster, E. A. Bielinski, N. Hazari, M. C. Holthausen, W. D. Jones, S. Schneider, S. ACS Catal. 2014, 4, 3994-4003. DOI:10.1021/cs5009656

10. P. J. Bonitatibus, Jr., S. Chakraborty, M. D. Doherty, O. Siclovan, W. D. Jones, G. L. Soloveichik, Proc. Natl. Acad. Sci. U. S. A. 2015, 112, 1687-1692. DOI:10.1073/pnas.1420199112

11. G. Zhang, S. K. Hanson, Org. Lett. 2013, 15, 650-653. DOI:10.1021/ol303479f

12. G. Zhang, K. V. Vasudevan, B. L. Scott, S. K. Hanson, J. Am. Chem. Soc. 2013, 135, 8668-8681. DOI:10.1021/ja402679a

13. S. Elangovan, M. Garbe, H. Jiao, A. Spannenberg, K. Junge, M. Beller, Angew. Chem., Int. Ed. 2016, 55, 15364-5368. DOI:10.1002/anie.201607233

14. M. Andérez-Fernández, L. K. Vogt, S. Fischer, W. Zhou, H. Jiao, M. Garbe, S. Elangovan, K. Junge, H. Junge, R. Ludwig, M. Beller, Angew. Chem., Int. Ed. 2017, 56, 559-562. DOI:10.1002/anie.201610182

15. N. V. Kulkarni, Jones, W. D. Chemistry of Mn and Co pincer compounds, in: D. M. Morales (Ed), Pincer Compounds: Chemistry and Applications, 2018, pp 491-518. DOI:10.1016/B978-0-12-812931-9.00024-4

16. S. Chakraborty, P. E. Piszel, W. W. Brennessel, W. D. Jones, Organometallics 2015, 34, 5203-5206.

DOI:10.1021/acs.organomet.5b00824

17. Z. Dai, Q. Luo, H. Jiang, Q. Luo, H. Li, J. Zhang, T. Peng, Catal. Sci. Technol. 2017, 7, 2506-2511. DOI:10.1039/C7CY00432J

18. V. Percec, G. M. Golding, J. Smidrkal, O. Weichold, J. Org. Chem. 2014, 69, 3447-3452. DOI:10.1021/jo049940i

19. H. Ke, X. Chen, G. Zou, J. Org. Chem. 2014, 79, 7132-7140. DOI:10.1021/jo501291y

20. X. Chen, H. Ke, G. Zou, ACS Catalysis 2014, 4, 379-385. DOI: $10.1021 / \operatorname{cs} 4009946$

21. S. D. Ramgren, L. Hie, Y. Ye, N. K. Garg, Org. Let. 2013, 15, 3950-3953. DOI:10.1021/ol401727y 
22. P. Leowanawat, N. Zhang, M. Safi, D. J. Hoffman, M. C. Fryberger, A. George, V. Percec, J. Org. Chem. 2012, 77, 28852892. DOI:10.1021/jo3001194

23. L. Gan, T. L Groy, P. Tarakeshwar, S. K. S. Mazinani, J. Shearer, V. Mujica, A. K Jones, J. Am. Chem. Soc. 2015, 137, 11091115. DOI: $10.1021 / \mathrm{ja} 509779 \mathrm{q}$

24. K. E. Dalle, J. Warnan, J. J. Leung, B. Reuillard, I. S. Karmel, E. Reisner, Chem. Rev. 2019, 119, 2752-2875.

DOI:10.1021/acs.chemrev.8b00392

25. T. Li, B. Xie, J.-X. Cao, D. -L. Zhang, C. Lai, H.-J. Fan, B. Zhao, W.-Y. Mou, X.-X. Bai, Appl. Organomet. Chem. 2021, 35, 26123-26124.

26. A.I. Vogel. A Text book of Quantitative Inorganic Analysis, 3rd Edn, Longmans Green and Co. Ltd., London, 1961.

27. M. Jimenez-Tenorio, M. C. Puerta, S. Valerga, D. L. Hughes, J. Chem. Soc. Dalton Trans. 1994, 2431-2436.

28. G. Booth, J. Chatt, J. Chem. Soc. 1965, 3238-3241. DOI:10.1039/jr9650003238

29. S. C. Davies, S. E. Duff, D. J. Evans, Acta Cryst. 2005, E61, m1674-m1676. DOI:10.1107/S160053680502386X

30. F. Scott, C. Krüger, P. Betz, J. Organomet. Chem. 1990, 387, 113-121.

31. S. Venkatesh, R. R. Panicker, V. Lenin Kumar, B. B. Pavankumar, N. Viswanath, S. Singh, R. Desikan, A. Sivaramakrishna, J. Coord. Chem. 2020, 73, 2963-2977.

DOI:10.1080/00958972.2020.1837784

32. J. Montgomery, Science of Synthesis, Georg Thieme Verlag KG, 2001, vol. 1, pp. 11.

33. B. Stewart, A. Harriman, L. J. Higham, Organometallics 2011, 30, 5338-5343. DOI:10.1021/om200070a

34. C. A. Tolman, Chem. Rev. 1977, 77, 313-348. DOI:10.1021/cr60307a002

35. A. Chacko, U. R. Idem, C. H. Bains, L. M. Mihichuk, A. L. L. East, Organometallics, 2013, 32, 5374-5383.

DOI:10.1021/om400667t

36. M. Kumar, R. V. Chaudhari, B. Subramaniam, T. A. Jackson, Organometallics, 2015, 34, 1062-1073.

DOI:10.1021/om5012775
37. C. P. Casey, G. T. Whiteker, M. G. Melville, L. M. Petrovich, J. A. Gavney, D. R. Powell, J. Am. Chem. Soc. 1992, 114, 55355543. DOI:10.1021/ja00040a008

38. W. N. M. van Leeuwen, P. C. J. Kamer, J. N. H. Reek, P. Dierkes, Chem. Rev. 2000, 100, 2741-2770.

DOI:10.1021/cr9902704

39. K. B. Wiberg, L. S. Crocker, K. M. Morgan, J. Am. Chem. Soc. 1991, 113, 3447-3450. DOI:10.1021/ja00009a033

40. L. A. Watson, O. Eisenstein, J. Chem. Educ. 2002, 79, 1269-1277. DOI:10.1021/ed079p1269

41. N. V. Kulkarni, W. W. Brennessel, W. D. Jones, ACS Catal. 2018, 8, 997-1002. DOI:10.1021/acscatal.7b03653

42. S. L. Scott, ACS Catal. 2018, 8, 8597-8599. DOI:10.1021/acscatal.8b03199

43. M. Zhao, Z. Yu, S. Yan, Y. Li, Tetrahedron Let. 2009, 50, 4624462. DOI:10.1016/j.tetlet.2009.05.100

44. S. Chandra, A. Kumar, P. K. Tomar. J. Saudi Chem. Soc., 2014, 18, 437-442. DOI:10.1016/j.jscs.2011.09.008

45. V. M. Chernyshev, A. V. Astakhov, I. E. Chikunov, R. V. Tyurin, D. B. Eremin, G. S. Ranny, V. N. Khrustalev, V. P. Ananikov, ACS Catal. 2019, 9, 2984-2995.

DOI:10.1021/acscatal.8b03683

46. B. J. Hornstein, J. D. Aiken, R. G. Finke, Inorg. Chem. 2002, 41, 1625-1638. DOI:10.1021/ic010920y

47. N. A. Eberhardt, H. Guan. Chem. Rev. 2016, 116, 8373-8426. DOI:10.1021/acs.chemrev.6b00259

48. N. V. Kulkarni, C. Dash, N. B. Jayaratna, S. G. Ridlen, S. K. Khani, A. Das, X. Kou, M. Yousufuddin, T. R. Cundari, H. V. R. Dias, Inorg. Chem. 2015, 54, 11043-11045. DOI:10.1021/acs.inorgchem.5b02134

49. P. G. Gassman, D. W. Macomber, S. M. Willging, J. Am. Chem. Soc. 1985, 107, 2380-2388. DOI:10.1021/ja00294a031

50. G. Reshma, V. Padmanabhan, A. R. Varma, M. S. Gouri, U. R. Nair, P. B. Parvathy, N. V. Kulkarni, D. Senthurpandi, J. Mol. Struct. 2021, 1226, 129344.

DOI:10.1016/j.molstruc.2020.129344

\section{Povzetek}

Proučili smo katalitično učinkovitost sistema nikel(II)-difosfin pri dehidrogenaciji 1-feniletanola do acetofenona brez prisotnosti akceptorja. Ugotovili smo, da imajo sterični in elektronski faktorji fosfinskega liganda pomemben vpliv na katalitične lastnosti sistema, pomembna pa je tudi izbira baze ter reakcijskih pogojev (čas reakcije, temperatura, stehiometrija). Glede na preliminarne analize predvidevamo homogen mehanizem, morda z udeležbo zvrsti, ki vsebuje nikljev hidrid. Nizke konverzije so posledica zmanjšanja katalitične aktivnosti sistema zaradi počasnega razkroja katalitične zvrsti. Med proučevanimi katalizatorji ima največjo konverzijo (52\%) katalizator C4, dikloro(1,2-bis(difenilfosfino) etan)nikel(II) (5 mol\%), ob dodatku $50 \mathrm{~mol} \%$ natrijevega etoksida v toluenu pri $120^{\circ} \mathrm{C}$.

Except when otherwise noted, articles in this journal are published under the terms and conditions of the Creative Commons Attribution 4.0 International License 